\title{
Decrease of Pollen Stainability of Green Bean at High Temperatures and Relationship to Heat Tolerance
}

\author{
Katsumi Suzuki, Tadashi Tsukaguchi, Hiroyuki Takeda, and Yoshinobu Egawa \\ Japan International Research Center for Agricultural Sciences, Ishigaki, Okinawa, 907-0002 Japan
}

\begin{abstract}
AdDitional INDEX WORDS. heat stress, pod set
Abstract. Pod yield of 'Kentucky Wonder' green bean (Phaseolus vulgaris L.) decreased at high temperatures due to a reduction of pod set. A highly positive correlation was observed between pod set and pollen stainability in flowers that were affected by heat stress about 10 days before anthesis. Pollen stainability was decreased by heat stress applied 8 to 11 days before flowering under controlled environment conditions. When mean air temperature during this period exceeded $28{ }^{\circ} \mathrm{C}$, pollen stainability decreased under field conditions. Low pollen stainability indicated sensitivity to high temperatures about 10 days before flowering. A heat-tolerant cultivar showed higher pollen stainability than did heat-sensitive cultivars under high temperatures. These results demonstrated that heat tolerance at an early reproductive stage could be evaluated by analyzing pollen stainability using flowers developed under high temperatures.
\end{abstract}

Many crop species can be damaged by high temperatures (Hall, 1992). Green bean (Phaseolus vulgaris) is a heat-sensitive crop and pod yield is decreased at high temperatures (Dickson and Boettger, 1984; Nakano et al., 1997).

High temperatures during the reproductive growth stage result in a reduction in pod and seed set in green bean (Phaseolus vulgaris) due to enhanced abscission of flower buds, flowers, and pods (Konsens et al., 1991; Monterroso and Wien, 1990). Degeneration of the embryo sac due to lack of fertilization is one of the main reasons for flower abscission (Ormrod et al., 1967). Pollen is more affected by heat stress than the ovule (Monterroso and Wien, 1990). Weaver et al. (1985) reported a close relationship between pollen stainability and tolerance to high temperature stress among bean selections. Pollen staining by acetocarmine has been used widely for rapid determination of pollen sterility occurring under environmental stresses (Marks, 1954; Takagaki et al., 1995). In the present investigation, greenhouse and growth chamber studies were conducted to analyze the relationship between pollen stainability and pod set of green bean after heat stress. We also examined changes in pollen stainability in the field using green bean cultivars known to differ in regard to heat tolerance.

\section{Materials and Methods}

GREENHOUSE AND GROWTH CHAMBER EXPERIMENTS. 'Kentucky Wonder' green beans were grown in 3.7-L plastic pots containing soil in a greenhouse from October to December 1998 with $12 \mathrm{~h}$ days/ $12 \mathrm{~h}$ nights of $27 / 23^{\circ} \mathrm{C}$. A natural photoperiod was provided and ranged from 10 to $11 \mathrm{~h}$. Thirty pots were prepared and one plant was grown in each pot. The medium in each pot was amended with $3 \mathrm{~g}$ of calcium carbonate and $3 \mathrm{~g}$ of a $15 \mathrm{~N}-12.5 \mathrm{P}-6.5 \mathrm{~K}$ slow-release fertilizer (CDUs555; Chisso Co., Tokyo, Japan). Plants were irrigated daily. After some flowers opened, all flowers were removed until $1 \mathrm{~d}$ before the onset of heat treatment. No pods were present when the treatments were administered. Fifteen plants were exposed to a high temperature of $32{ }^{\circ} \mathrm{C} / 28{ }^{\circ} \mathrm{C}$ for $24 \mathrm{~h}$ in a growth chamber (TGE-9H-S, Tabai Espec Co. Osaka, Japan) with a $12 \mathrm{~h}$ photoperiod of $1000 \mu \mathrm{mol} \cdot \mathrm{m}^{-2} \cdot \mathrm{s}^{-1}$ photosynthetically active radiation $(P A R)$ from a metal halide lamp as measured using a quantum meter (LI-250; Meiwa Co. Osaka, Japan). Relative humidity was

Received for publication 2 Aug. 2000. Accepted for publication 22 May 2001. The cost of publishing this paper was defrayed in part by the payment of page charges. Under postal regulations, this paper therefore must be hereby marked advertisement solely to indicate this fact.
$70 \% \pm 5 \%$. Exposure to high temperature was initiated at $0900 \mathrm{HR}$ and the plants were transferred back to the greenhouse at $0900 \mathrm{HR}$ the next day. The other plants remained in the greenhouse, as control plants. Every day for 2 weeks after the high temperature treatment, pod set and pollen stainability were examined.

Pod set ratio was determined according to the method of Nakano et al. (1998) with some modification. Pod set was determined as the ratio of the total number of pods set $4 \mathrm{~d}$ after flowering to the total number of flowers in both the high temperature and control treatments. The total number of flowers examined for pod set during a $14 \mathrm{~d}$ period was 1161 .

For determination of pollen stainability, three to 10 flower buds were fixed in 1 acetic acid : 3 ethanol (v/v) $1 \mathrm{~d}$ before flowering. Six to ten anthers from each flower bud were squashed in acetocarmine. Pollen stainability was assessed based on the percentage of wellstained pollen grains. At least 100 pollen grains for each flower bud were used to determine pollen stainability. One flower bud was regarded as a replication, and means and LSD values were calculated.

MONITORING POD SET IN FLOWERS THAT WERE EXAMINED FOR POLLEN STAINABILITY. 'Kentucky Wonder' green beans were grown in a greenhouse in the same manner as described previously. After the first flower opened, each six plants were transferred to a growth chamber (FLT-1001L; Tokyo-rikakikai Co., Tokyo, Japan) for exposure to selected high day/night temperatures of $37 / 33^{\circ} \mathrm{C}, 33 / 29$ ${ }^{\circ} \mathrm{C}$, or $29 / 25^{\circ} \mathrm{C}$, with a 12 -h photoperiod of $1000 \mu \mathrm{mol} \cdot \mathrm{m}^{-2} \cdot \mathrm{s}^{-1}(P A R)$ from high-pressure sodium lamps for $24 \mathrm{~h}$ as measured at plant level using a quantum meter (LI-250; Meiwa Co. Osaka, Japan). Relative humidity was $70 \% \pm 5 \%$. Pollen stainability and pod set were determined using flowers that opened 8 to $11 \mathrm{~d}$ after high temperature treatment. The anthers were collected from each flower and stained with acetocarmine for observing pollen stainability. The flowers examined for pollen stainability were labeled and pod set was then examined $5 \mathrm{~d}$ later. Pod set ratio was calculated as a percentage of pods set per more than 10 flowers that showed similar pollen stainability $( \pm 5 \%)$.

EXAMINATION OF POLLEN STAINABILITY UNDER FIELD CONDITIONS. The Japan International Research Center for Agricultural Sciences (JIRCAS) Okinawa Subtropical Station, located on Ishgaki Island, Okinawa, Japan, (lat. $24^{\circ} 20^{\prime} \mathrm{N}$, long. $124^{\circ} \mathrm{E}$, altitude $20 \mathrm{~m}$ ) experiences subtropical conditions. At this station, the heat-tolerant green bean cultivar Haibushi was developed from an accession collected in southeast Asia by screening 350 breeding lines and cultivars (Nakano et al., 1997). 'Haibushi' has a higher yield potential than do commercial cultivars as seen in local adaptability trials conducted in 


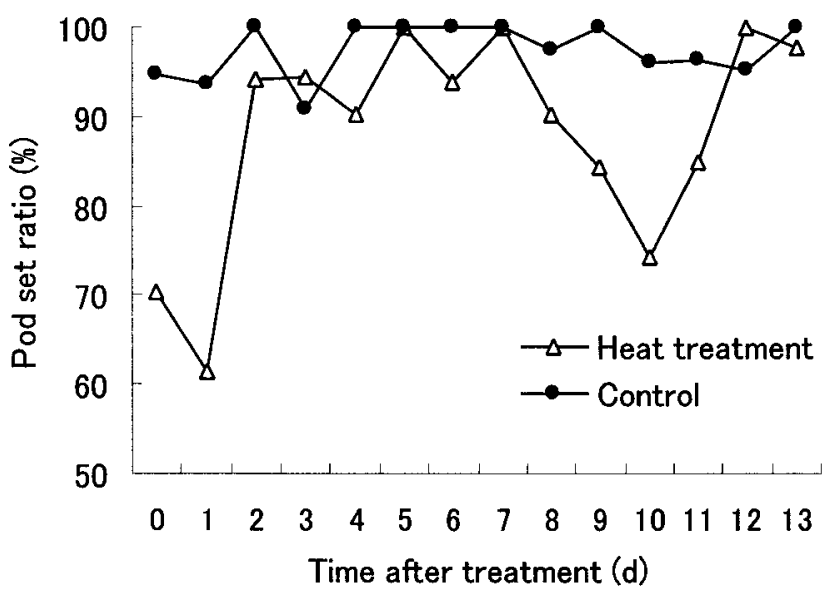

Fig. 1. Changes in pod set ratio of 'Kentucky Wonder' green bean following a 1d heat treatment at $32 / 28{ }^{\circ} \mathrm{C}$ and then returned to a greenhouse at $27 / 23{ }^{\circ} \mathrm{C}$. Control plants remained in the greenhouse and received no heat treatment.

several areas of southern Japan (Nakano et al., 1997). In the present study we investigated pollen stainability of 'Haibushi' during summer cultivation and compared it with that of other cultivars. 'Haibushi', 'Kentucky Wonder', 'Oregon', and 'Okinawa Local' were grown in a field at JIRCAS Okinawa Subtropical Station. Each cultivar was cultivated three times from January to July 1998 (Table 1). 'Okinawa Local' is a local cultivar grown in Okinawa prefecture located in the southernmost part of Japan. 'Kentucky Wonder' and 'Oregon' are commercial cultivars grown in Japan. The experimental field was covered with an insect exclusion net. One block of each cultivar was $5 \times 1 \mathrm{~m}$ and three replications were arranged in a randomized complete block design. Eight to $10 \mathrm{~d}$ after flowering, pods were harvested daily for about 3 weeks. For examining pollen stainability, 3 to 16 flower buds were fixed $1 \mathrm{~d}$ before flowering in 1 acetic acid : 3 ethanol (v/v) every week throughout the flowering period for each cropping, and stored at $4{ }^{\circ} \mathrm{C}$ in a refrigerator. Pollen stainability was determined for each flower bud, and means and LSDS were calculated. One flower bud was regarded as a replication.

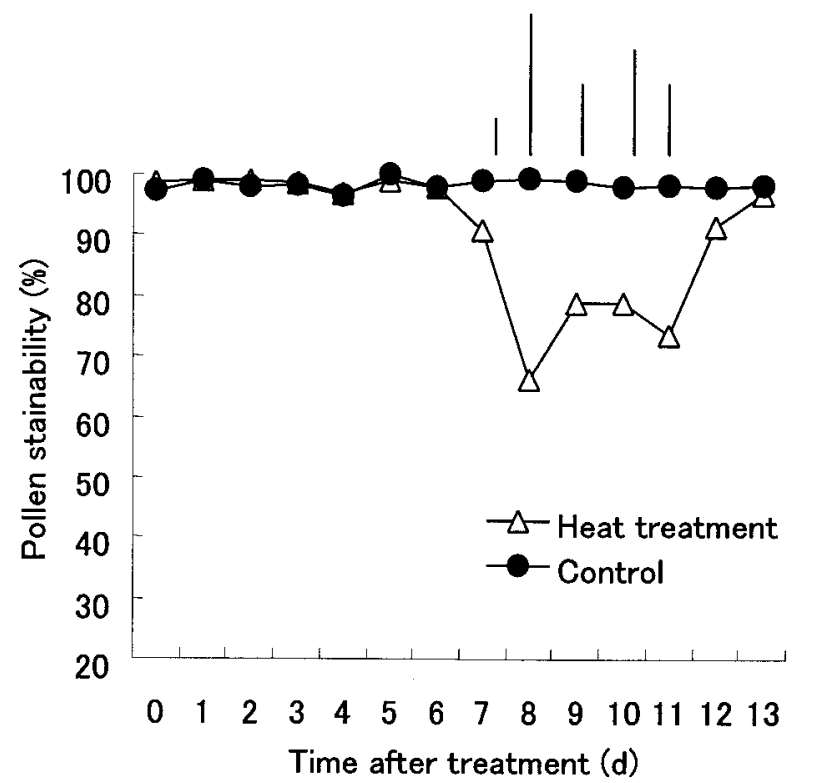

Fig. 2. Changes in percentage of pollen stainability in flowers of 'Kentucky Wonder' green bean following a $1-\mathrm{d}$ heat treatment at $32 / 28^{\circ} \mathrm{C}$ then returned to a greenhouse at $27 / 23^{\circ} \mathrm{C}$. Control plants remained in the greenhouse and received no heat treatment. Vertical bars indicate LSD values $(P=0.05)$.

\section{Results}

RELATIONSHIP BETWEEN POD SET RATIO AND POLLEN STAINABILITY UNDER CONTROLLED ENVIRONMENT CONDITIONS. On the first day, and 8 to $11 \mathrm{~d}$ after high temperature treatment $\left(32 / 28^{\circ} \mathrm{C}\right)$, pod set was reduced by $60 \%$ and $70 \%$, respectively (Fig. 1). Such reductions were not observed in pods set from 2 to $7 \mathrm{~d}$ and later than $12 \mathrm{~d}$ after application of the high temperature treatment. In the same plants, pollen stainability decreased 8 to $11 \mathrm{~d}$ after high temperature treatment (Fig. 2). No decrease in pollen stainability was observed before $6 \mathrm{~d}$ or after $13 \mathrm{~d}$. In the control plants, pollen stainability was almost $100 \%$. While the decrease in pod set from 8 to $11 \mathrm{~d}$ after high temperature treatment corresponded to the decrease in pollen stainability, no decrease in pollen stainability was observed $1 \mathrm{~d}$ after high temperature treatment when pod set was markedly reduced.

MONITORING POD SET IN FLOWERS IN WHICH POLLEN STAINABILITY WAS DETERMINED. Pollen stainability of flower buds exposed to various temperatures 8 to $11 \mathrm{~d}$ before flowering and pod set were plotted (Fig. 3). A highly positive correlation $(r=0.98, P<0.01)$ was observed between pollen stainability and pod set (Fig. 3).

CHANGE IN POLLEN STAINABILITY DURING CULTIVATION AND RELATIONSHIP WITH AIR TEMPERATURE IN THE FIELD. Maximum, minimum, and average air temperatures in the field increased gradually from June to mid-July (Fig. 4). Mean air temperature was $>28^{\circ} \mathrm{C}$ after June 13.

Pollen stainability was <20\% in 'Kentucky Wonder', 'Oregon', and 'Okinawa Local' after mid-June (Fig. 5). Although pollen stainability of the heat-tolerant cultivar Haibushi also decreased in mid-June, it had recovered to about $60 \%$ by the end of June (Fig. 5).

The relationship between pollen stainability of two cultivars, Haibushi and Kentucky Wonder, and mean air temperature during 8 to $11 \mathrm{~d}$ before flowering was analyzed. When the air temperature 8 to $11 \mathrm{~d}$ before flowering exceeded $28^{\circ} \mathrm{C}$, pollen stainability of the heat tolerant cultivar Haibushi was higher than that of the heatsensitive cultivar Kentucky Wonder (Fig. 6).

Pod yield, mean air temperature, and pollen stainability varied depending on the time of cultivation (Table 1). Mean air temperatures during the harvest period of the first, second, and third cropping were $25.7,27.9$, and $29.8^{\circ} \mathrm{C}$, respectively.

Pod yield of all cultivars decreased as the mean temperature

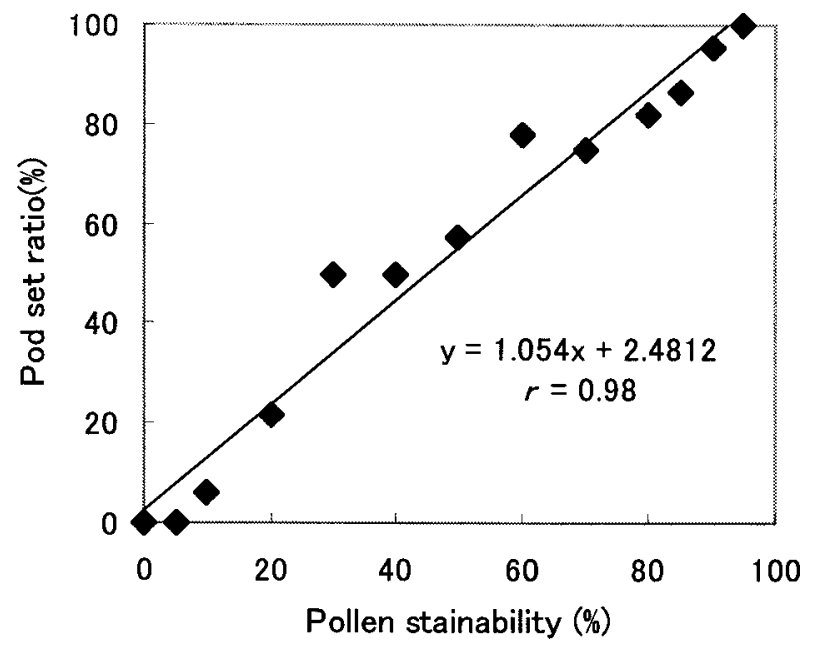

Fig. 3. Relationship between pollen stainability and pod set ratio for flowers of 'Kentucky Wonder' green bean exposed to temperatures ranging from 8 to 11 $\mathrm{d}$ before flowering. Pod set was determined using the same flower whose pollen stainability was examined. 


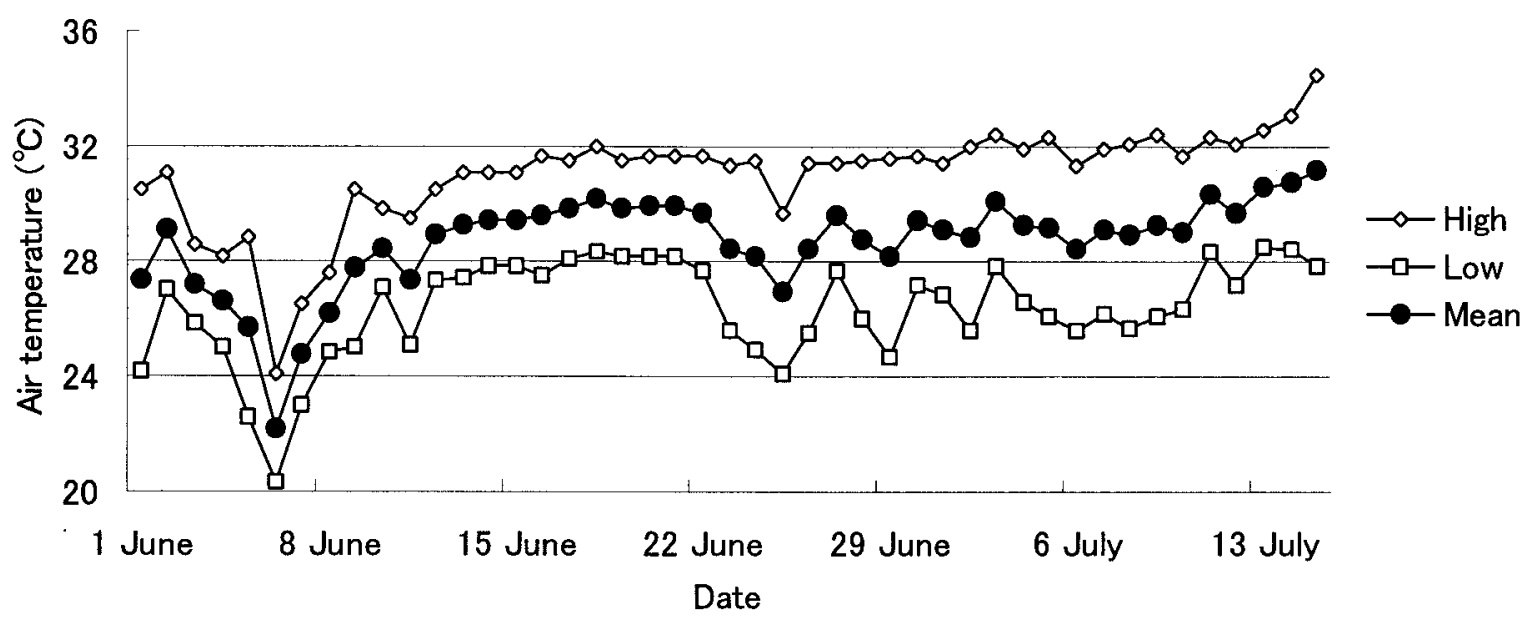

three cultivars decreased to $<20 \%$, that of 'Haibushi' was $>60 \%$.

\section{Discussion}

Pod yield of green bean decreasedunderhigh temperature conditions. Pollen stainability also decreased when mean air temperature exceeded 28 ${ }^{\circ} \mathrm{C}$ (Fig. 6). The

Fig. 4. Changes in air temperature from 1 June to 13 July 1998.

increased. In the second cropping, pod yields of 'Haibushi', 'Oregon', and 'Kentucky Wonder' decreased 58\%, 64\%, and 13\%, respectively, compared to the first cropping. In the third cropping, 'Haibushi' still produced $24 \%$ of the yield of the first cropping, while pod production of 'Okinawa Local', 'Oregon', and 'Kentucky Wonder' was completely depressed.

As mean air temperature during the flowering period of each cropping increased, pollen stainability decreased (Table. 1). In the first cropping, 'Haibushi', 'Oregon' and 'Kentucky Wonder' showed pollen stainability $>80 \%$. While pollen stainability of 'Okinawa Local', 'Oregon', and 'Kentucky Wonder' decreased to 55\%, 73\%, and $65 \%$ in the second cropping, respectively, that of 'Haibushi' was still $>75 \%$. In the third cropping, though the pollen stainability of the
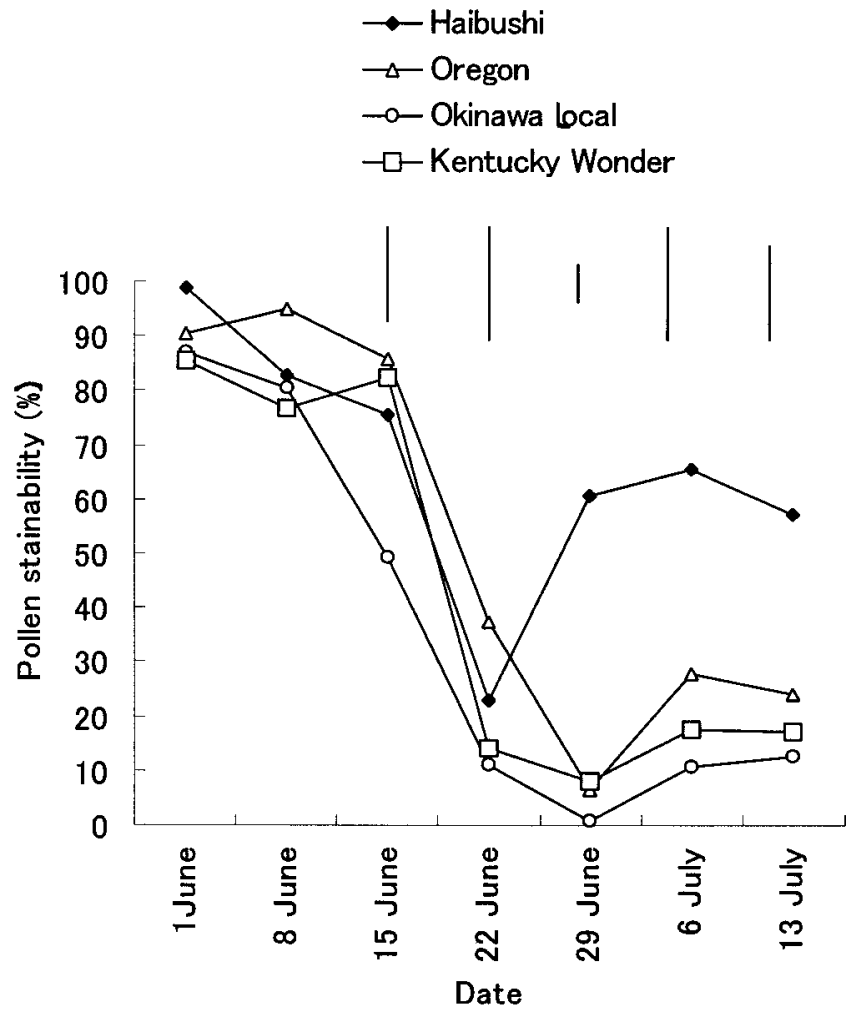

Fig. 5. Changes in pollen stainability of selected cultivars of green bean during different periods of cultivation. Vertical bars indicate LSD values $(P=0.05)$ reduction of pod yield was attributed to the decrease of pollen stainability since a high correlation was observed between pollen stainability and pod set (Fig. 3). Thus, we conclude that the decrease of pollen stainability due to high temperatures led to an abscission of the plants' reproductive organs, resulting in yield reduction. Previous studies have also showed that high temperatures reduced pod production in green bean (Konsens et al. 1991; Nakano et al., 1998). Halterlein et al. (1980) reported that pollen stainability in green bean was reduced by heat stress. Weaver et al. (1985) suggested a close relationship between pollen stainability and tolerance to high-temperature stress among bean selections. Pollen was damaged to a greater extent by heat stress than were the female flower organs (Monterroso and Wien, 1990).

Pollen stainability was reduced by exposure to high air temperatures 8 to $11 \mathrm{~d}$ before flowering, resulting in a reduction of pod set (Figs. 1 and 2). The period of 8 to $11 \mathrm{~d}$ before flowering corresponds to the early microspore stage in green bean (Watanabe, 1953). Pollen tetrads are produced normally under high temperature conditions, but pollen begins to degenerate morphologically after the uninucleate stage and finally aborts (Suzuki et al. 1999). In rice (Oryza sativa L.), the early microspore stage has also been found to be very sensitive to heat and cold stresses (Satake and Hayase, 1970; Satake and Yoshida, 1978). In tomato (Lycopersicon esculentum Mill.), it has been reported that meiosis became irregular due to heat

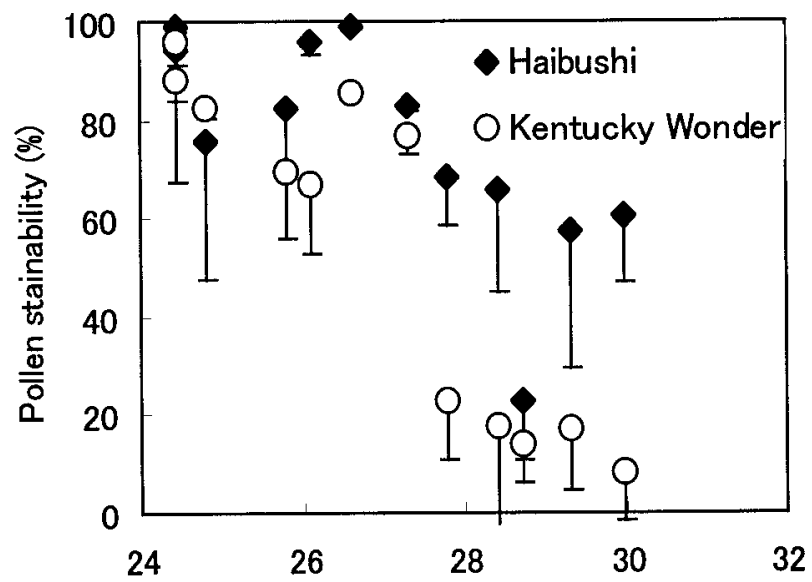

Average air temperature $8-11 \mathrm{~d}$ before flowering $\left({ }^{\circ} \mathrm{C}\right)$

Fig. 6. Relationship between average air temperature 8 to $11 \mathrm{~d}$ before flowering and pollen stainability of 'Haibushi' and 'Kentucky Wonder' green bean under field conditions. 
Table 1. Yield of pods and average pollen stainability of green bean during three periods of cultivation.

\begin{tabular}{|c|c|c|c|c|c|c|}
\hline \multirow[b]{3}{*}{ Cultivar } & \multicolumn{6}{|c|}{ Harvest period } \\
\hline & \multicolumn{2}{|c|}{14 Apr.-12 May $^{z}$} & \multicolumn{2}{|c|}{26 May-25 June ${ }^{y}$} & \multicolumn{2}{|c|}{ June-3 Aug. ${ }^{\mathrm{x}}$} \\
\hline & $\begin{array}{l}\text { Yield } \\
\left(\mathrm{t} \cdot \mathrm{ha}^{-1}\right)\end{array}$ & $\begin{array}{c}\text { Pollen stainability (\%) } \\
\text { (16-23 Apr.) }\end{array}$ & $\begin{array}{l}\text { Yield } \\
\left(\mathrm{t} \cdot \mathrm{ha}^{-1}\right)\end{array}$ & $\begin{array}{l}\text { Pollen stainability (\%) } \\
\text { (27 May-22 June) }\end{array}$ & $\begin{array}{l}\text { Yield } \\
\left(t \cdot h a^{-1}\right)\end{array}$ & $\begin{array}{c}\text { Pollen stainability (\%) } \\
\text { (29 June-13 July) }\end{array}$ \\
\hline Haibushi & 11.4 & 90.7 & 6.6 & 75.2 & 2.8 & 61.3 \\
\hline Okinawa Local & $---{ }^{w}$ & --- & 5.5 & 55.8 & 0 & 8.0 \\
\hline Oregon & 8.0 & 96 & 5.1 & 73.0 & 0 & 19.5 \\
\hline Kentucky Wonder & 10.5 & 83 & 1.4 & 65.1 & 0 & 14.3 \\
\hline
\end{tabular}

${ }^{\mathrm{z}}$ Seeding date $27 \mathrm{Feb}$. Mean air temperature during harvest period $=25.2^{\circ} \mathrm{C}$.

${ }^{y}$ Seeding date $10 \mathrm{Apr}$. Mean air temperature during harvest period $=27.7^{\circ} \mathrm{C}$.

${ }^{x}$ Seeding date 13 May Mean air temperature during harvest period $=29.8^{\circ} \mathrm{C}$.

wNo data.

stress (Iwahori, 1965). On the other hand, high temperature did not lead to meiotic abnormalities in cowpea (Vigna unguiculata (L.) Walp. ssp. unguiculata), though microspores were not viable under high temperature (Warrag and Hall, 1984). It has been reported that pollen sterility in cowpea is caused by early degeneration of the tapetum tissue at high temperatures (Ahmed et al. 1992).

A reduction of pod set was observed in flowers that opened 1 $\mathrm{d}$ after heat treatment. This reduction may indicate sensitivity of the female flower parts. In tomato, Peet et al. (1997) noted that a decrease in fruit set occurred at temperatures $>28^{\circ} \mathrm{C}$, when fertile pollen was applied to male-sterile plants grown under a range of high temperature stress conditions. This reduction may also be attributed to depression of pollen germination on the stigma and/ or pollen release by heat stress as reported in tomato (Sato et al., 2000). Pollen tube elongation in the style may also be damaged by heat stress.

In the present study, yield reduction was accompanied by lower pollen stainability. The heat-tolerant cultivar Haibushi showed high pod yield and high pollen stainability under high temperature conditions (Figs. 5 and 6). Nakano et al. (2000) reported that heat acclimation occurred in heat-tolerant cultivars of green bean but did not occur in heat-sensitive cultivars. Heattolerant lines of tomato have been seen to maintain a higher level of pollen fertility throughout the growing season than do heatsensitive lines (Dane, et al., 1991). In the present study, the most high temperature-sensitive stage during pollen development of green bean occurred 8 to $11 \mathrm{~d}$ before flowering by examining pollen stainability. We propose that examination of pollen stainability is an effective means for evaluating green bean cultivars for heat tolerance and their high yield capacity under heat stress.

\section{Literature Cited}

Ahmed, F.E., A.E. Hall, and D.A. Demason. 1992. Heat injury during floral development in cowpea (Vigna unguiculata, Fabaceae). Amer. J. Bot. 79:784-791.

Dane, F., A.G. Hunter, and O.L. Chambliss. 1991. Fruit set, pollen fertility, and combining ability of selected tomato genotypes under high-temperature field conditions. J. Amer. Soc. Hort. Sci. 116:906910.

Dickson, M. and M. Boettger. 1984. Heat tolerance in snap beans. Annu. Rpt. Bean Improvement Coop. 27:125.

Hall, A.E. 1992. Breeding for heat tolerance, 129-168. In: J. Janick (ed.). Plant breeding reviews. vol. 10. Wiley, New York.

Halterlein, A.J., C.D. Clayberg, and I.D. Teare. 1980. Influence of high temperature on pollen grain viability and pollen tube growth in the styles of Phaseolus vulgaris L. J. Amer. Soc. Hort. Sci. 105:12-14.

Iwahori, S. 1965. High temperature injuries in tomato. IV. Development of normal flower buds and morphological abnormalities of flowers treated with high temperature. J. Jpn. Soc. Hort. Sci. 34:33-41.

Konsens, I., M. Ofir, and J. Kigel. 1991. The effect of temperature on the production and abscission of flowers and pods in snap bean (Phaseolus vulgaris L.) Ann. Bot. 67:391-399.

Marks, G.E. 1954. An aceto-carmine glycerol jelly for use in pollen fertility counts. Stain Technol. 29:277.

Monterroso, V.A. and H.C. Wien. 1990. Flower and pod abscission due to heat stress in beans. J. Amer. Soc. Hort. Sci. 115:631-634.

Nakano, H., M. Kobayashi, and T. Terauchi. 1998. Sensitive stages to heat stress in pod setting of common bean (Phaseolus vulgaris L.). Jpn. J. Trop. Agr. 42:78-84.

Nakano, H., M. Kobayashi, and T. Terauchi. 2000. Heat acclimation and de-acclimation for pod setting in heat-tolerant varieties of common bean (Phaseolus vulgaris L.). Jpn. J. Trop. Agr. 44:123-129.

Nakano, H., T. Momonoki, T. Miyashige, H. Otsuka, T. Hanada, A. Sugimoto, H. Nakagawa, M. Matsuoka, T. Terauchi, M. Kobayashi, M. Oshiro, K. Yasuda, N. Vanichwattanarumruk, S. Chotechuen, and D. Boonmalison. 1997. 'Haibushi': A new variety of snap bean tolerant to heat stress. Jpn. Intl. Res. Center Agr. Sci. J. 5:1-12.

Ormrod, D.P., C.J. Woolley, G.W. Eaton, and E.H. Stobbe. 1967. Effect of temperature on embryo sac development in Phaseolus vulgaris $\mathrm{L}$. Can. J. Bot. 45:948-950.

Peet, M.M., D.H. Willits, and R. Gardner. 1997. Response of ovule development and post-pollen production processes in male-sterile tomatoes to chronic, sub-acute high temperature stress. J. Expt. Bot. 48:101-111.

Satake, T. and H. Hayase. 1970. Male sterility caused by cooling treatment at the young microspore stage in rice plants. V. Estimations of pollen developmental stage and the most sensitive stage to coolness. Jpn. J. Crop Sci. 39:468-473.

Satake, T. and S. Yoshida. 1978. High temperature-induced sterility in Indica rices at flowering. Jpn. J. Crop Sci. 47:6-17.

Sato, S., M. M. Peet, and J. F. Thomas. 2000. Physiological factors limit fruit set of tomato (Lycopersicon esculentum Mill.) under chronic, mild heat stress. Plant, Cell Environ. 23:719-726.

Suzuki, K., T. Takeda, S. Matuura, S. You, and Y. Egawa. 1999. Morphological study on injury of pollen of snap bean by heat stress. Proc. Intl. Symp. 'World Food Security'. p. 203-206.

Takagaki, M., M. Kakinuma, and T. Ito. 1995. Effect of temperature on pollen fertility and pollen germination of three pepper (Capsicum annuиm L.) varieties (in Japanese). Jpn. J. Trop. Agr. 39:247-249.

Warrag, M.O.A. and A.E. Hall. 1984. Reproductive responses of cowpea (Vigna unguiculata (L.) Walp. ) to heat stress. II. Responses to night air temperature. Field Crops Res. 8:17-33.

Watanabe, H. 1953. Studies on the unfruitfulness of the beans. II. Influence of the temperature on the flower bud differentiation and blooming (in Japanese). J. Jpn. Soc. Hort. Sci. 22:36-42.

Weaver, M.L., H. Timm, M.J. Silbernagel, and D.W. Burke. 1985. Pollen staining and high-temperature tolerance of bean. J. Amer. Soc. Hort. Sci. 110:797-799. 